\title{
First-Principles Insights into the Interface Chemistry between 4-Aminothiophenol and Zinc Phosphide $\left(\mathrm{Zn}_{3} \mathrm{P}_{2}\right)$ Nanoparticles
}

\author{
Nelson Y. Dzade*(1) \\ Cardiff University, Main Building, Park Place, CF10 3AT Cardiff, U.K. \\ Supporting Information
}

\begin{abstract}
Accurate prediction of the structures, stabilities, and electronic structures of hybrid inorganic/organic systems is an essential prerequisite for tuning their electronic properties and functions. Herein, the interface chemistry between the 4-aminothiophenol (4ATP) molecule and the (001), (101), and (110) surfaces of zinc phosphide $\left(\mathrm{Zn}_{3} \mathrm{P}_{2}\right)$ has been investigated by means of first-principles density functional theory calculation with a correction for van der Waals interactions. In particular, the atomic-level insights into the fundamental aspects of the 4ATP adsorption, including the lowest-energy adsorption configurations, binding energetics, structural parameters, and electronic properties are presented and discussed. The 4ATP molecule is demonstrated to bind most strongly onto the least stable $\mathrm{Zn}_{3} \mathrm{P}_{2}(001)$ surface $\left(E_{\text {ads }}=-1.91 \mathrm{eV}\right)$ and least strongly onto the most stable $\mathrm{Zn}_{3} \mathrm{P}_{2}(101)$ surface $\left(E_{\text {ads }}=-1.21 \mathrm{eV}\right)$. Partial density of states analysis shows that the adsorption of $4 \mathrm{ATP}$ on the $\mathrm{Zn}_{3} \mathrm{P}_{2}$ surfaces is characterized by strong hybridization between the molecule's sulfur and nitrogen p-orbitals and the d-orbitals of the interacting surface $\mathrm{Zn}$ ions, which gave rise to electron density accumulation around the centers of the newly formed $\mathrm{Zn}-\mathrm{S}$ and $\mathrm{Zn}-\mathrm{N}$ chemical bonds. The thermodynamic crystal morphology of the nonfunctionalized and 4ATP-functionalized $\mathrm{Zn}_{3} \mathrm{P}_{2}$ nanoparticles was obtained using Wulff construction based on the calculated surface energies. The stronger binding of the 4ATP molecule onto the less stable (001) and (110) surfaces in preference to the most stable (101) facet resulted in the modulation of the $\mathrm{Zn}_{3} \mathrm{P}_{2}$ nanocrystal shape, with the reactive (001) and (110) surfaces becoming more pronounced in the equilibrium morphology.
\end{abstract}

\section{INTRODUCTION}

Zinc phosphide is an attractive earth-abundant solar absorber material for scalable thin-film photovoltaic applications owing to its direct band gap of $1.5 \mathrm{eV},{ }^{1}$ high visible-light absorption coefficient $\left(>10^{4} \mathrm{~cm}^{-1}\right),{ }^{2,3}$ long minority-carrier diffusion length $(\sim 10 \mu \mathrm{m}),{ }^{4}$ high extinction coefficient, ${ }^{5}$ passive grain boundaries, ${ }^{6}$ and large range of potential doping concentrations $\left(10^{13}\right.$ to $\left.10^{18} \mathrm{~cm}^{-3}\right){ }^{7}$ Despite its ideal optoelectronic properties, problems such as poor band-alignment with buffer layers, inadequate interface passivation, ${ }^{8,9}$ and low surface stability in the presence of moisture and oxygen ${ }^{10,11}$ remain major problems that severely limits the commercial fabrication of highly efficient $\mathrm{Zn}_{3} \mathrm{P}_{2}$-based photovoltaics. Zinc phosphide nanoparticles can easily get oxidized when in contact with water and oxygen owing to the higher specific surface area and higher reactivity relative to the bulk. ${ }^{12-14}$ It is therefore important to develop synthesis techniques to protect $Z_{3} \mathrm{P}_{2}$ surfaces against unwanted oxidation.

Efforts have been made to passivate $\mathrm{Zn}_{3} \mathrm{P}_{2}$ surfaces via in situ functionalization, wherein the $\mathrm{Zn}_{3} \mathrm{P}_{2}$ nanoparticles of thin films are exposed to a vapor of organic functional molecules immediately after synthesis. ${ }^{15-18}$ Functionalization of $\mathrm{Zn}_{3} \mathrm{P}_{2}$ nanoparticles can enhance their surface stability against temperature and possible oxidation in the presence of oxygen and moisture that could result in their degradation. ${ }^{19,20}$ The binding of the organic molecules to the nanoparticle crystal facets helps to dictate the growth mechanism in terms of rate, final size, or geometric shape. ${ }^{21}$ Various functional groups react differently with inorganic surfaces, with the common example being thiol to gold. ${ }^{15,22}$ Strongly binding molecules can form a dense protective layer and hence stabilize the nanoparticles better than weakly binding ones.

A molecular-level insight into the adsorption mechanism of organic molecules onto inorganic surfaces and nanostructures is a prerequisite for the development of novel hybrid devices. However, due to the complex nature of the interface between organic functional groups and semiconductor nanoparticle surfaces, the interface chemistry is difficult to determine by purely experimental means. Accurate first-principles density functional theory (DFT) calculations have, however, become indispensable in complementing experiments to elucidate the interactions of organic molecules with solid surfaces. ${ }^{21-24}$ In this work, first-principles dispersion-corrected DFT-D3 calculations have been employed to investigate the functionalization of the (001), (101), and (110) surfaces of $\mathrm{Zn}_{3} \mathrm{P}_{2}$ by adsorbed 4-aminothiophenol (4ATP) molecule. Different coupling

Received: August 24, 2019

Accepted: November 6, 2019

Published: January 6, 2020 
schemes that involve one or more functional groups of the 4ATP molecule have been investigated in order to determine the preferred lowest energy adsorption configuration. The optimized structures, binding energetics, and electronic properties of the $4 \mathrm{ATP}-\mathrm{Zn}_{3} \mathrm{P}_{2}$ complexes are discussed. Finally, based on calculated surface energies the thermodynamic crystal morphology of the nonfunctionalized and functionalized $\mathrm{Zn}_{3} \mathrm{P}_{2}$ nanoparticle were simulated using Wulff construction. $^{25}$

\section{COMPUTATIONAL DETAILS}

The first-principles DFT calculations were performed using the Vienna $\mathrm{Ab}$ initio Simulation Package. ${ }^{26-28}$ The projected augmented wave method m $^{29,30}$ was used to describe the interactions between the valence and cores electrons. The electronic exchange-correlation potential was calculated using the Perdew-Burke-Ernzerhof generalized gradient approximation (GGA) functional. ${ }^{31-35}$ In our calculations, the longrange van der Waals (vdW) interactions were taken into consideration using the method of Grimme (DFT-D3). ${ }^{36}$ This is important because the standard LDA/GGA approximations fail to provide an accurate description of the asymptotic decreasing behavior of the long-range vdW interactions that are ubiquitous in hybrid inorganic/organic systems. ${ }^{37-40} \mathrm{~A}$ plane-wave basis set with a kinetic energy cut-off of $600 \mathrm{eV}$ was tested to be sufficient to converge the total energy of $\mathrm{Zn}_{3} \mathrm{P}_{2}$ to within $10^{-6} \mathrm{eV}$ and the residual Hellmann-Feynman forces on all relaxed atoms reached $10^{-3} \mathrm{eV} \AA^{-1}$. The Brillouin zone of the bulk $\mathrm{Zn}_{3} \mathrm{P}_{2}$ was sampled using $5 \times 5 \times 3$ Monkhorst$\mathrm{Pack}^{41} \mathrm{~K}$-point mesh, which ensures electronic and ionic convergence.

The bulk $\mathrm{Zn}_{3} \mathrm{P}_{2}$ was modeled in the tetragonal system with space group $\mathrm{P}_{2} / \mathrm{nmc}\left(D_{4 h}^{15}\right)$ and lattice parameters: $a=b=$ $8.089 \AA, c=11.396 \AA$ (Figure 1a). ${ }^{42-45}$ The primitive unit cell

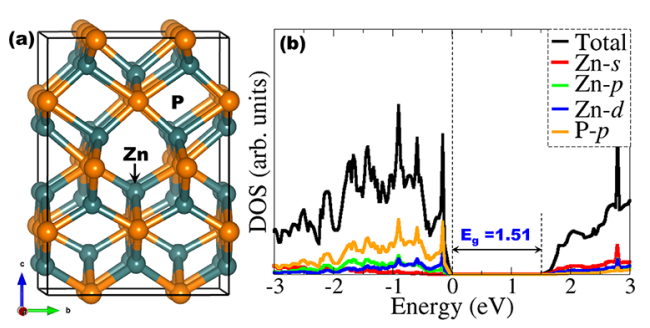

Figure 1. (a) Tetragonal unit cell of $\mathrm{Zn}_{3} \mathrm{P}_{2}$ with space group $P 4_{2} / n m c$ $\left(D_{4 h}^{15}\right)$ and (b) partial DOS calculated with HSE06 functional.

containing $16 \mathrm{P}$ atoms and $24 \mathrm{Zn}$ atoms. A full unit cell relaxation yielded strain-free $\mathrm{Zn}_{3} \mathrm{P}_{2}$ with lattice parameters $a=$ $b=8.029 \AA$, $c=11.336 \AA$, which compares closely with known experimental data. ${ }^{42-45}$ To overcome the limitation of standard DFT methods in accurately predicting the electronic band gap of semiconducting materials, the screened hybrid DFT functional with $25 \%$ Hartree-Fock exchange ${ }^{46}$ was employed to determine the electronic structure of $\mathrm{Zn}_{3} \mathrm{P}_{2}$ (Figure $1 \mathrm{~b}$ ). The band gap is predicted at $1.51 \mathrm{eV}$, which is in excellent agreement with the experiment ${ }^{1}$ and previous DFT predictions. ${ }^{8,47}$ The partial density of states (PDOS) plot shows that the valence band is dominated by the electronic states of the Zn-pd and P-p orbitals, whereas the conduction band is composed mainly of the $\mathrm{Zn}$-sd orbitals.

The (001), (101), and (110) surfaces were considered for the investigation of the 4ATP molecule adsorption as they are the most commonly observed growth facets of $\mathrm{Zn}_{3} \mathrm{P}_{2}$ nanocrystals. ${ }^{16,48}$ The surfaces were created from the fully relaxed bulk using the METADISE code, ${ }^{49}$ which ensures the creation of surfaces with zero dipole moment perpendicular to the surface plane. ${ }^{50}$ However, due to the adsorption of 4ATP on only one side of the slabs, the Makov-Payne dipole correction $^{51}$ perpendicular to the surfaces was applied to correct any net charge or monopole/dipole perpendicular to the surfaces, which might otherwise affect the adsorption energetics and structures. The (001) surface has three unique terminations, whereas the (101) and (110) surfaces have two, unique possible terminations, all of which were considered and fully relaxed in order to determine the most stable terminations. For each surface, the slab thickness was increased until the convergence of the surface energy was achieved within $1 \mathrm{meV}$ per cell. The converged slab thickness of the (001), (101), and (110) surfaces is 22.67, 19.65, and 17.02 $\AA$, respectively. A vacuum region of $20 \AA$ was tested to be large enough to avoid any spurious interactions between periodic slabs.

The relaxed structure of the most stable termination of each surface is schematically shown in Figure 2, whereas the relaxed

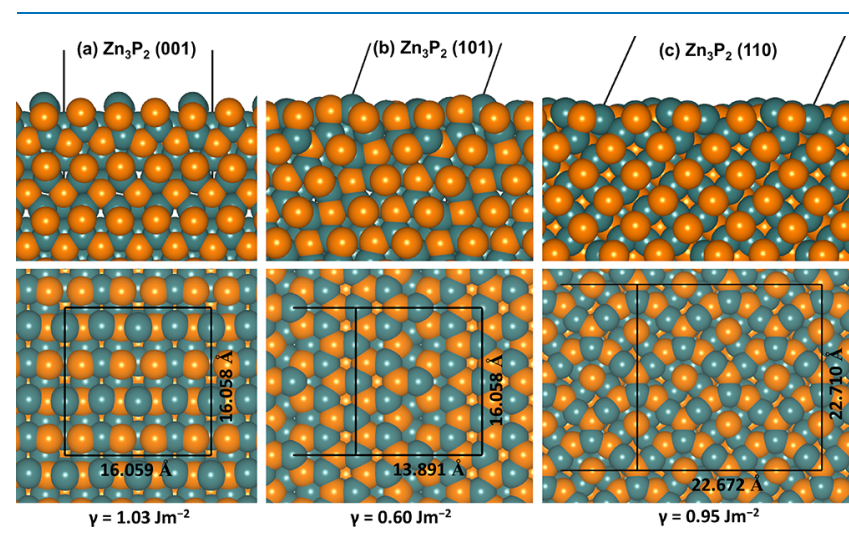

Figure 2. Side and top views of the relaxed structures of $\mathrm{Zn}_{3} \mathrm{P}_{2}(00)$, (101), and (110) surfaces used for the adsorption of the 4ATP molecule. (Color scheme: $\mathrm{Fe}=$ grey, $\mathrm{S}=$ yellow). The size of the simulation cells is highlighted by the continuous black lines.

structures of all possible terminations of each surface are shown in Supporting Information Figures S1-S3. Shown in Table 1 are the calculated unrelaxed and relaxed surface energies of all unique terminations of each surface with their corresponding percentage relaxation. The surface energy of the most stable terminations of the (001), (101), and (110)

Table 1. Unrelaxed $\left(\gamma_{\text {unrelaxed }}\right)$ and Relaxed $\left(\gamma_{\text {Relaxed }}\right)$ Surface Energies of the (001), (101), and (110) Surfaces of $\mathrm{Zn}_{3} \mathrm{P}_{2}{ }^{a}$

$\begin{array}{ccccc}\text { surface } & \text { termination } & \gamma_{\text {unrelaxed }}\left(\mathrm{J} \mathrm{m}^{-2}\right) & \gamma_{\text {relaxed }}\left(\mathrm{J} \mathrm{m}^{-2}\right) & \text { \% relaxation } \\ (001) & \mathrm{Zn} & 1.48 & 1.03 & 30.4 \\ & \mathrm{P}-(\mathrm{A}) & 1.67 & 1.18 & 29.3 \\ & \mathrm{P} \text {-(B) } & 1.89 & 1.48 & 21.7 \\ (101) & \mathrm{Zn}-(\mathrm{A}) & 0.90 & 0.60 & 33.3 \\ & \mathrm{Zn}-(\mathrm{B}) & 1.05 & 0.69 & 34.2 \\ (110) & & & & \\ & \mathrm{Zn} & 1.60 & 0.95 & 40.6 \\ & \mathrm{P} & 1.73 & 1.17 & 32.2\end{array}$

${ }^{a_{T}}$ The effect of relaxation is quantified as \% relaxation 
surfaces is calculated to be $1.03,0.60$, and $0.95 \mathrm{~J} \mathrm{~m}^{-2}$, respectively, which suggest that the surface stability trend in decreasing order is $(101)>(110)>(001)$. Each surface is found to under significant relaxation as reflected in the calculated percentage relaxation. The significant percentage relaxation is ascribed to relaxation of topmost undercoordinated ions, which shift downward to provide a closer to bulk coordination of the surface species.

The 4ATP adsorption calculations were carried out on surfaces with large areas (as shown in Figure 2) in order to minimize lateral interactions between the 4ATP molecules in neighboring image cells. No symmetry constraints were imposed on the structural optimization of the $4 \mathrm{ATP}-\mathrm{Zn}_{3} \mathrm{P}_{2}$ systems, and in particular, the 4ATP molecule was free to move away laterally and vertically from its initial binding site or reorient itself to find the lowest-energy adsorption configuration. The adsorption energy $\left(E_{\mathrm{ads}}\right)$, which characterizes the strength of $4 \mathrm{ATP}-\mathrm{Zn}_{3} \mathrm{P}_{2}$ interactions, is calculated as follows

$$
E_{\mathrm{ads}}=E_{4 \mathrm{ATP}+\text { surface }}-\left(E_{\text {surface }}+E_{4 \mathrm{ATP}}\right)
$$

where $E_{4 \mathrm{ATP}+\text { surface }}$ is the total energy of the relaxed adsorbatesubstrate systems, $E_{\text {surface }}$ is the total energy of the isolated surface, and $E_{4 \mathrm{ATP}}$ is the total energy of the free 4ATP molecule. An exothermic adsorption process is characterized by a negative $E_{\text {ads }}$, whereas an endothermic adsorption process is characterized by a positive value. Prior to the adsorption of 4ATP on the (001), (101), and (110) $\mathrm{Zn}_{3} \mathrm{P}_{2}$ surfaces, the reference energy and bond length were computed in a cubic box of size $20 \AA$, sampling only the gamma point. The fully relaxed structure of the 4ATP molecule is shown in Figure 3a,
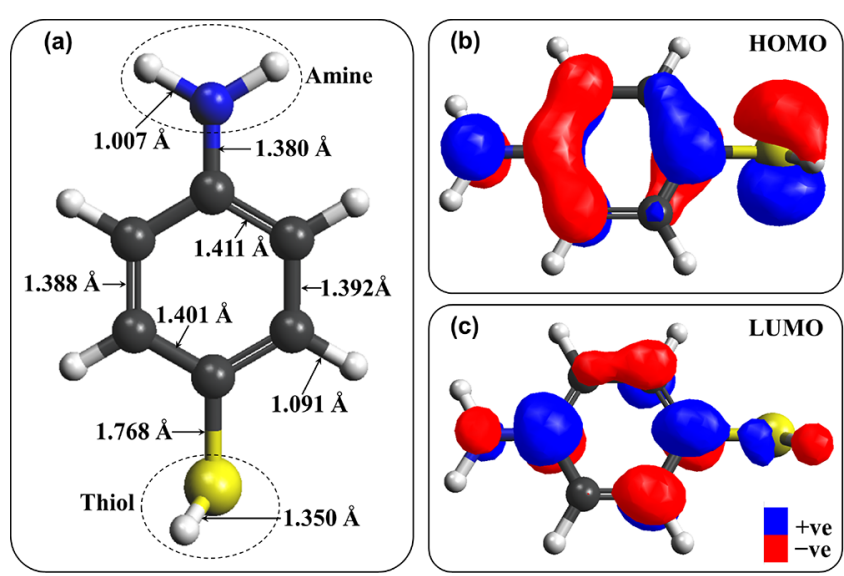

Figure 3. Schematic representation of (a) the optimized structure, (b) the LUMO, and (c) the HOMO of 4ATP $\left(\mathrm{C}_{6} \mathrm{H}_{7} \mathrm{NS}\right)$. The amine $\left(-\mathrm{NH}_{2}\right)$ and thiol $(-\mathrm{SH})$ end groups are highlighted in dashed circles. (Color scheme: $\mathrm{C}=$ grey, $\mathrm{S}=$ orange and $\mathrm{H}=$ white).

with the optimized $\mathrm{C}-\mathrm{C}, \mathrm{C}-\mathrm{S}, \mathrm{C}-\mathrm{N}, \mathrm{C}-\mathrm{H}, \mathrm{S}-\mathrm{H}$, and $\mathrm{N}-\mathrm{H}$ bond distances displayed. The highest occupied molecular orbital (HOMO) and the lowest unoccupied molecular orbital (LUMO) of 4ATP (Figure 3b,c) show a dominant contribution from the $3 p$ orbitals of the sulfur atom, and from the $2 \mathrm{p}$ orbitals of $\mathrm{N}$ and $\mathrm{C}$ atoms. These orbitals are expected to dictate the reactivity of the 4ATP molecule unto the $\mathrm{Zn}_{3} \mathrm{P}_{2}$ surfaces.

Atomic-level insight into the adsorption mechanism of 4ATP at the $\mathrm{Zn}_{3} \mathrm{P}_{2}$ surfaces was analyzed through PDOS and differential charge density $(\Delta \rho)$ iso-surface contours. Bader charge analysis was used to quantify any charge transfers between the $4 \mathrm{ATP}-\mathrm{Zn}_{3} \mathrm{P}_{2}$ systems. ${ }^{52}$ The equilibrium morphology of the $\mathrm{Zn}_{3} \mathrm{P}_{2}$ nanocrystals were determined using Wulff's construction based on calculated surface energies. ${ }^{53}$ Under thermodynamic conditions, the equilibrium morphology of a crystal possesses the minimal total surface free energy for a given volume based on Gibbs formulation. The relaxed surface energy of the naked surfaces $\left(\gamma_{\mathrm{r}}\right)$ was calculated using the equation

$$
\gamma_{\mathrm{r}}=\frac{E_{\text {slab }}^{\text {relaxed }}-n E_{\text {bulk }}}{2 A}
$$

where $E_{\text {slab }}^{\text {relaxed }}$ is the energy of the relaxed slab, $n E_{\text {bulk }}$ is the energy of an equal number $(n)$ of the bulk $\mathrm{Zn}_{3} \mathrm{P}_{2}$ atoms, and $A$ is the surface area. After the adsorption of 4ATP on one side of the surface slab $(1 \times A)$, the additional energy because of the relaxed surface at the top of the slab with the adsorbed 4ATP molecule must be separated from the energy of the fully relaxed naked surface, as the two differ. From the relaxed surface energy of the naked surface and considering negligible relaxation at the bottom of the slab (held fixed), it is possible to calculate the surface energy of the 4ATP-functionalized surfaces as

$$
\gamma_{4 \mathrm{ATP}}=\frac{E_{\text {slab }+4 \mathrm{ATP}}^{\text {relaxed }}-n E_{4 \mathrm{ATP}}-n E_{\text {bulk }}}{A}-\frac{E_{\text {slab }}^{\text {relaxed }}-n E_{\text {bulk }}}{2 A}
$$

where $E_{\text {slab+4ATP }}^{\text {relaxed }}$ is the energy of the surface with adsorbed 4ATP molecule and $n E_{4 \mathrm{ATP}}$ is the energy of the equivalent number of free 4ATP molecules in the gas phase. Based on the calculated surface energies, the equilibrium Wulff morphology for the naked and 4ATP-functionalized surfaces was constructed using GDIS software. ${ }^{55}$ Because of the small difference between the entropies of bulk materials and the surface, the contribution of the excess entropy term to the surface free energy is small. ${ }^{56}$ Hence for solid surfaces, the surface energy is a close approximation of the surface free energy which can be assumed to determine the equilibrium morphology of the nanocrystal. This approach has been employed to investigate the effect of the adsorption of small molecules on the thermodynamic morphologies of many different materials, including oxides, carbonates, phosphates, sulfides, and metal nanoparticles, ${ }^{54,56-59}$ where good agreement was obtained with the experiment.

\section{RESULTS AND DISCUSSION}

3.1. Adsorption of 4ATP on the $\mathrm{Zn}_{3} \mathrm{P}_{2}$ (001) Surface. 4ATP molecule has three potential binding groups; the thiol $(-\mathrm{SH})$, amine $\left(-\mathrm{NH}_{2}\right)$ end groups, and the benzene $\left(-\mathrm{C}_{6}\right)$ ring (Figure $3 \mathrm{a}$ ), thus it may form single or multiple bonds with $\mathrm{Zn}_{3} \mathrm{P}_{2}$ surface species. In order to determine the preferred adsorption sites and binding modes of the 4ATP molecule on the (001) surface, a number of different initial orientations were optimized without any symmetry constraints. Shown in Figure 4 are the optimized adsorption structures and the calculated adsorption energies, interatomic bond distances, and charge transfer are listed in Table 2. Two monodentate configurations, wherein the 4ATP molecule binds at the $\mathrm{Zn}$ site either via the $-\mathrm{SH}\left(\mathrm{Zn}-\mathrm{S}\right.$-slanted) or $-\mathrm{NH}_{2}(\mathrm{Zn}-\mathrm{N}$ slanted) end, and a bidentate configuration, wherein it binds via both the $-\mathrm{NH}_{2}$ and $-\mathrm{SH}$ ends $(\mathrm{Zn}-\mathrm{NS}-\mathrm{Zn})$, were predicted. No stable chemisorbed structure involving the benzene ring was obtained. The lowest energy adsorption 
(a) Zn-S-slanted

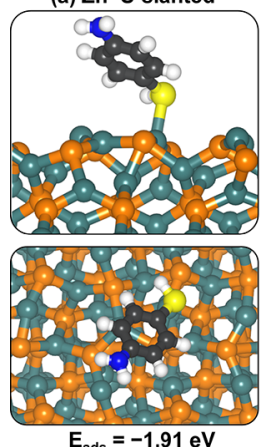

(b) Zn-NS-Zn-flat

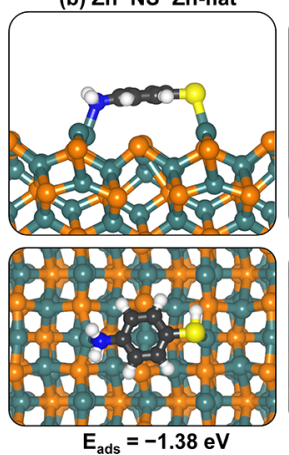

(c) Zn-N-slanted

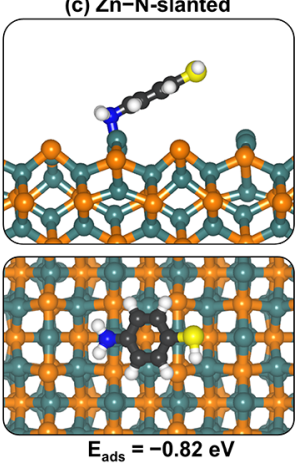

Figure 4. Lowest energy adsorption configurations of 4ATP on $\mathrm{Zn}_{3} \mathrm{P}_{2}(001)$ surface: (a) monodentate $\mathrm{Zn}-\mathrm{S}$-slanted, (b) bidentate $\mathrm{Zn}-\mathrm{NS}-\mathrm{Zn}$-flat, and (c) monodentate $\mathrm{Zn}-\mathrm{N}$-slanted, in side (top) and top (bottom) views. (Color scheme: $\mathrm{Zn}=$ green, $\mathrm{P}=$ orange, $\mathrm{S}=$ yellow; $\mathrm{C}=$ grey, and $\mathrm{H}=$ white).

structure on the (001) surface is predicted to the monodentate $\mathrm{Zn}-\mathrm{S}$-slanted configuration (Figure $4 \mathrm{a}$ ), which released an adsorption energy of $-1.91 \mathrm{eV}$, compared to $-1.48 \mathrm{eV}$ for the bidentate $\mathrm{Zn}-\mathrm{NS}-\mathrm{Zn}$ configuration (Figure $4 \mathrm{~b}$ ) and $-0.82 \mathrm{eV}$ for the monodentate $\mathrm{Zn}-\mathrm{N}$-slanted configuration (Figure 4c). The interacting $\mathrm{Zn}-\mathrm{S}$ bond distance in the most stable $\mathrm{Zn}-\mathrm{S}$ slanted configuration is calculated at $2.458 \AA$, whereas in the $\mathrm{Zn}-\mathrm{N}$-slanted configuration, the $\mathrm{Zn}-\mathrm{N}$ bond distance is 2.109 $\AA$. In the bidentate $\mathrm{Zn}-\mathrm{NS}-\mathrm{Zn}$ configuration, the interacting $\mathrm{Zn}-\mathrm{S}$ and $\mathrm{Zn}-\mathrm{N}$ bond distances are 2.503 and $2.187 \AA$, respectively. The calculated $\mathrm{Zn}-\mathrm{S}$ interatomic distances at the $\mathrm{Zn}_{3} \mathrm{P}_{2}$ (001) surface are similar to those of cysteine metal-S bonds, which are typically predicted in the range of 2.50$2.520 \AA$ for $\mathrm{Au}-\mathrm{S}$ interaction. ${ }^{60,61}$ Shown in Table 2 are the calculated internal bond distances of the adsorbed 4ATP molecule on the (001) surface. When compared to the gas phase geometry parameters, one can observe only small adsorption-induced changes in the internal bond distances. The adsorbed 4ATP molecule remained planar with only small tilting in the hydrogen atoms of the $-\mathrm{NH}_{2}$ end away from the surface. The topology of the surface also remained essentially preserved with only small lateral and vertical displacements of the interacting surface species.

3.2. Adsorption of 4ATP on the $\mathrm{Zn}_{3} \mathrm{P}_{2}$ (101) Surface. Similar to the (101) surface, a number of different initial orientations of the 4ATP molecule were optimized on the (101) surface without any symmetry constraints, in order to determine the preferred adsorption sites and the lowest-energy adsorption configurations. Shown in Figure 5 are the three stable adsorption configurations predicted with the calculated

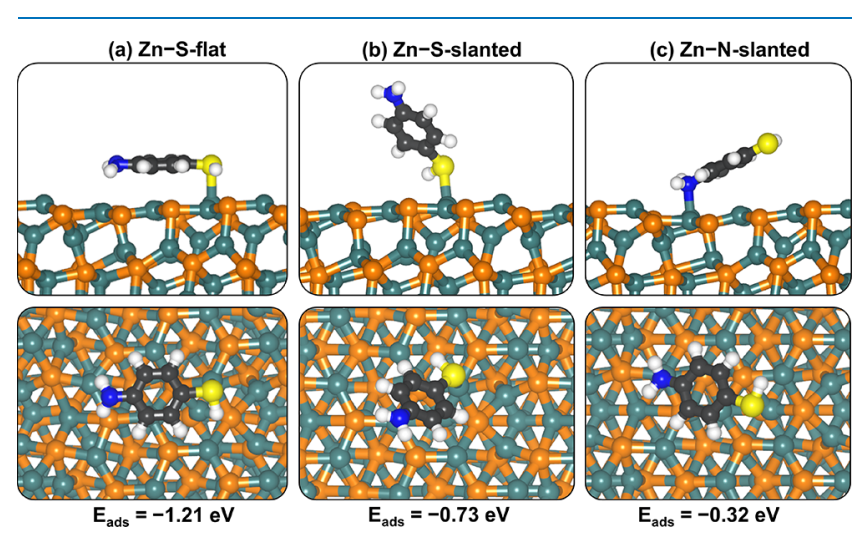

Figure 5. Lowest energy adsorption configurations of 4ATP on $\mathrm{Zn}_{3} \mathrm{P}_{2}(101)$ surface: (a) monodentate $\mathrm{Zn}-\mathrm{S}$-flat, (b) monodentate $\mathrm{Zn}-\mathrm{S}$-slanted, and (c) monodentate $\mathrm{Zn}-\mathrm{N}$-slanted, in side (top) and top (bottom) views. Color scheme: $\mathrm{Zn}=$ green, $\mathrm{P}=$ orange, $\mathrm{S}=$ yellow; $\mathrm{C}=$ grey, and $\mathrm{H}=$ white).

adsorption energies and structural parameters reported in Table 2. The strongest adsorption is computed for the $\mathrm{Zn}-\mathrm{S}$ flat configuration (Figure 5a) which released an adsorption energy of $-1.21 \mathrm{eV}$ compared to $-0.73 \mathrm{eV}$ for the $\mathrm{Zn}-\mathrm{S}$-slant (Figure $5 \mathrm{~b}$ ), and $-0.32 \mathrm{eV}$ for the $\mathrm{Zn}-\mathrm{N}$-slant (Figure $5 \mathrm{c}$ ) configurations. In the lowest energy $\mathrm{Zn}-\mathrm{S}$-flat configuration, the interacting $\mathrm{Zn}-\mathrm{S}$ bond distance is calculated at $2.482 \AA$, with the hydrogen atoms of the $-\mathrm{NH}_{2}$ end tilting toward the surface such the shorted $\mathrm{P} \cdots \mathrm{H}$ and $\mathrm{Zn} \cdots \mathrm{H}$ interatomic distance are predicted at 2.834 and $2.939 \AA$, respectively. In the $\mathrm{Zn}-\mathrm{S}$ slant configuration, the $\mathrm{Zn}-\mathrm{S}$ bond distance is calculated at $2.553 \AA$, whereas in the $\mathrm{Zn}-\mathrm{N}$-slant configuration, the $\mathrm{Zn}-\mathrm{N}$ distance is $2.203 \AA$. As on the (001) surface, the adsorbed 4ATP molecule remained planar with only small bending in the hydrogen atoms of the $-\mathrm{NH}_{2}$ end toward the surface in the $\mathrm{Zn}-\mathrm{S}$-slant configuration and away from the $\mathrm{Zn}-\mathrm{N}$-slant configuration. The surface topology remained essentially unchanged as reflected in only small vertical displacements (0.04-0.10 $\AA)$ of the interacting surface species.

3.3. Adsorption of 4ATP on the $\mathrm{Zn}_{3} \mathrm{P}_{2}$ (110) Surface. The predicted lowest energy adsorption structures of the 4ATP molecule on the $\mathrm{Zn}_{3} \mathrm{P}_{2}$ (110) surface are shown in Figure 6 with the energetics and structural details listed in Table 2. The lowest energy adsorption structure is predicted to be a bidentate configuration (Figure 6a), wherein the 4ATP

Table 2. Adsorption Energies $\left(E_{\text {ads }}\right)$ and the Relevant Bond Distances of 4ATP Adsorbed onto the (001), (101), and (110) $\mathrm{Zn}_{3} \mathbf{P}_{2}$ Surfaces $^{a}$

\begin{tabular}{|c|c|c|c|c|c|c|c|c|c|}
\hline surface & configuration & $E_{\text {ads }}(\mathrm{eV})$ & $d(\mathrm{Zn}-\mathrm{S})(\AA)$ & $d(\mathrm{Zn}-\mathrm{N})(\AA)$ & $d(\mathrm{C}-\mathrm{S})(\AA)$ & $d(\mathrm{C}-\mathrm{N})(\AA)$ & $d(\mathrm{~S}-\mathrm{H})(\AA)$ & $d(\mathrm{~N}-\mathrm{H})(\AA)$ & $|q|(e-)$ \\
\hline \multirow[t]{3}{*}{$\mathrm{Zn}_{3} \mathrm{P}_{2}(001)$} & Zn-S-slanted & -1.91 & 2.458 & & 1.776 & 1.389 & 1.354 & 1.013 & 0.11 \\
\hline & $\mathrm{Zn}-\mathrm{NS}-\mathrm{Zn}$-flat & -1.48 & 2.508 & 2.187 & 1.783 & 1.444 & 1.356 & 1.023 & 0.29 \\
\hline & $\mathrm{Zn}-\mathrm{N}$-slanted & -0.82 & & 2.109 & 1.767 & 1.436 & 1.348 & 1.022 & 0.06 \\
\hline \multirow[t]{3}{*}{$\mathrm{Zn}_{3} \mathrm{P}_{2}(101)$} & $\mathrm{Zn}-\mathrm{S}$-flat & -1.21 & 2.482 & 3.360 & 1.778 & 1.381 & 1.352 & 1.017 & 0.11 \\
\hline & Zn-S-slanted & -0.73 & 2.552 & & 1.779 & 1.388 & 1.353 & 1.012 & 0.07 \\
\hline & $\mathrm{Zn}-\mathrm{N}$-slanted & -0.32 & & 2.203 & 1.762 & 1.424 & 1.350 & 1.019 & 0.05 \\
\hline \multirow[t]{3}{*}{$\mathrm{Zn}_{3} \mathrm{P}_{2}(110)$} & $\mathrm{Zn}-\mathrm{NS}-\mathrm{Zn}$-flat & -1.35 & 2.649 & 2.230 & 1.775 & 1.435 & 1.349 & 1.010 & 0.14 \\
\hline & Zn-S-slanted & -0.82 & 2.504 & & 1.777 & 1.377 & 1.353 & 1.010 & 0.13 \\
\hline & $\mathrm{Zn}-\mathrm{N}$-slanted & -0.52 & & 2.133 & 1.766 & 1.431 & 1.349 & 1.021 & 0.08 \\
\hline
\end{tabular}

${ }^{a}|q|$ denotes the net charge gained by the 4ATP molecule 
(a) Zn-NS-Zn-flat

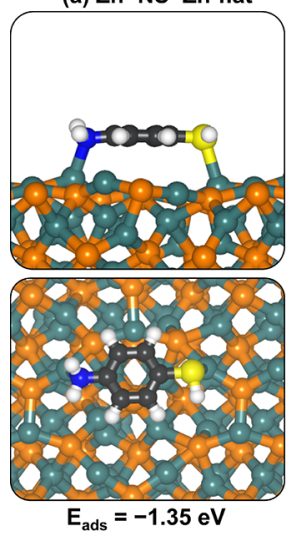

(b) Zn-S-slanted

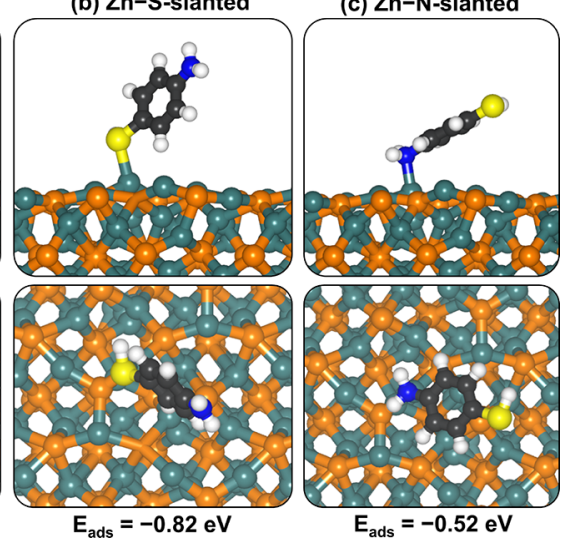

Figure 6. Lowest energy adsorption configurations of 4ATP on $\mathrm{Zn}_{3} \mathrm{P}_{2}(110)$ surface: (a) bidentate $\mathrm{Zn}-\mathrm{NS}-\mathrm{Zn}$-flat, (b) monodentate $\mathrm{Zn}-\mathrm{S}$-slanted, and (c) monodentate $\mathrm{Zn}-\mathrm{N}$-slanted, in side (top) and top (bottom) views. Color scheme: $\mathrm{Zn}=$ green, $\mathrm{P}=$ orange, $\mathrm{S}=$ yellow; $\mathrm{C}=$ grey, and $\mathrm{H}=$ white).

molecule binds at $\mathrm{Zn}$ sites via both the $-\mathrm{NH}_{2}$ and $-\mathrm{SH}$ ends (denoted as $\mathrm{Zn}-\mathrm{NS}-\mathrm{Zn}$ ). The adsorption energy is calculated at $-1.35 \mathrm{eV}$, with the interacting $\mathrm{Zn}-\mathrm{S}$ and $\mathrm{Zn}-\mathrm{N}$ bond distances calculated at 2.649 and $2.230 \AA$, respectively. The monodentate $\mathrm{Zn}-\mathrm{S}$-slant (Figure $6 \mathrm{~b}$ ) and $\mathrm{Zn}-\mathrm{N}$-slant (Figure 6c) configurations released adsorption energies of -0.82 and $-0.52 \mathrm{eV}$, respectively, and the interacting $\mathrm{Zn}-\mathrm{S}$ and $\mathrm{Zn}-\mathrm{N}$ bond distances are predicted at 2.504 and $2.133 \AA$, respectively. As was observed on the (001) and (101) surfaces, the adsorption of the 4ATP molecule on the (110) surface did not induce significant changes to the surface; the interacting surface species remained in their positions with only small vertical displacements $(0.03-0.09 \AA)$ relative to the naked surface. By comparing the adsorption characteristic of 4ATP on the three surfaces, the stronger adsorption calculated for the configurations involving the thiol $(-\mathrm{SH})$ end suggests that the $\mathrm{S}$ p-orbitals are the driving force for 4ATP adsorption on the $\mathrm{Zn}_{3} \mathrm{P}_{2}$ surfaces. This is consistent with the dominant contribution of the $3 p$ character of the sulfur atom to the HOMO of 4ATP (Figure 3b).

3.4. Electronic Properties. Atomic-level insights into the bonding mechanism of the 4ATP molecule onto the (001),

(101), and (110) $\mathrm{Zn}_{3} \mathrm{P}_{2}$ surfaces were gained through analyses of the PDOS and differential charge density isosurface contours, which give a chemical picture of hybridization and electron density redistribution within the $4 \mathrm{ATP}-\mathrm{Zn}_{3} \mathrm{P}_{2}$ systems. Shown in Figure $7 \mathrm{a} 1-\mathrm{cl}$ is the density of states projected on the sulfur and nitrogen p-orbitals of the 4ATP molecule in the lowest energy configurations at each surface and the interacting $\mathrm{Zn} \mathrm{p}$ - and d-states. Consistent with chemisorption, the PDOS plots reveal strong hybridization between the interacting surface and adsorbate orbitals, which gave rise to electron density redistributions within the 4ATP$\mathrm{Zn}_{3} \mathrm{P}_{2}$ systems. This was analyzed via differential charge density isosurface contours, obtained from relation

$$
\Delta \rho=\rho_{4 \mathrm{ATP}+\text { surface }}-\left(\rho_{\text {surface }}+\rho_{\text {4ATP }}\right)
$$

where $\rho_{4 \mathrm{ATP}+\text { surface }}$ is the electron density of the total 4ATP$\mathrm{Zn}_{3} \mathrm{P}_{2}$ system. $\rho_{\text {surface }}$ and $\rho_{4 \mathrm{ATP}}$ electron density of the naked $\mathrm{Zn}_{3} \mathrm{P}_{2}$ surface and that of the isolated 4ATP molecule with the atomic positions taken to be the same as those of the relaxed $4 \mathrm{ATP}-\mathrm{Zn}_{3} \mathrm{P}_{2}$ systems. The iso-surface contour plots displayed in Figure $7 \mathrm{a} 2, \mathrm{~b} 2, \mathrm{c} 2$ reveal electron density accumulation (green contours) around centers of the newly formed $\mathrm{Zn}-\mathrm{S}$ and $\mathrm{Zn}-\mathrm{N}$ chemical bonds. The observed electron density accumulation between hydrogen and surface atoms on the (101) surface (Figure 7b2) is characteristic of hydrogenbonded interactions, which may contribute to the stabilization of the 4ATP molecule on the surface. Notwithstanding the local electron density rearrangements within the $4 \mathrm{ATP}-\mathrm{Zn}_{3} \mathrm{P}_{2}$ systems, the net charge transfers between the $\mathrm{Zn}_{3} \mathrm{P}_{2}$ surfaces and the 4ATP molecule, as estimated from the Bader partition scheme is very small: $0.11 \mathrm{e}^{-}$on the (001) and (101) surfaces and $0.14 \mathrm{e}^{-}$on the (110) surface.

To ascertain whether the functionalization of the $\mathrm{Zn}_{3} \mathrm{P}_{2}$ surfaces have any effect on their electronic structures, the partial DOS of the naked surface was compared with those covered with the 4ATP molecule as shown in Figure 8. The semiconducting nature of the surfaces is found to be generally preserved upon 4ATP adsorption with only small differences in features compared to the naked surfaces. The band gap of the naked (001), (101), and (110) surfaces, calculated at 1.12, 1.15 , and $1.305 \mathrm{eV}$, respectively, remain essentially unchanged upon 4ATP adsorption. Any noticeable differences in features
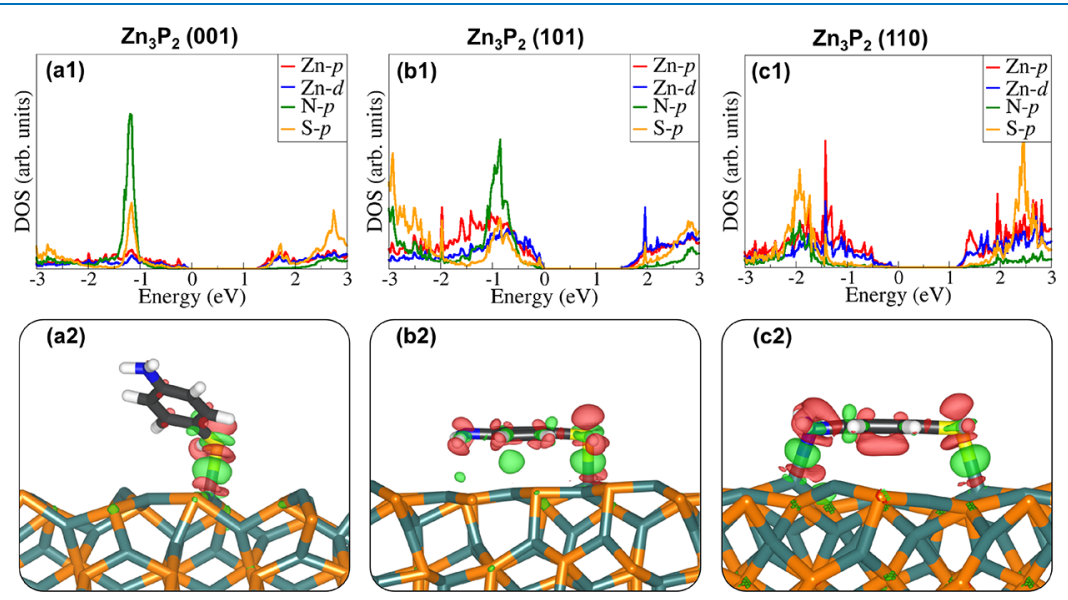

Figure 7. PDOS projected on the interacting surface $\mathrm{Zn} \mathrm{p}$ - and d-states and the 4ATP molecule's N and S p-states at the (a1) (001), (b1) (101), and (c1) (110) $\mathrm{Zn}_{3} \mathrm{P}_{2}$ surfaces. Shown in $(\mathrm{a} 2-\mathrm{c} 2)$ are the corresponding differential charge density isosurfaces contours, where red and green isosurfaces denote depletion and accumulation of electron density by $\pm 0.02 \mathrm{e} / \AA^{3}$, respectively. 


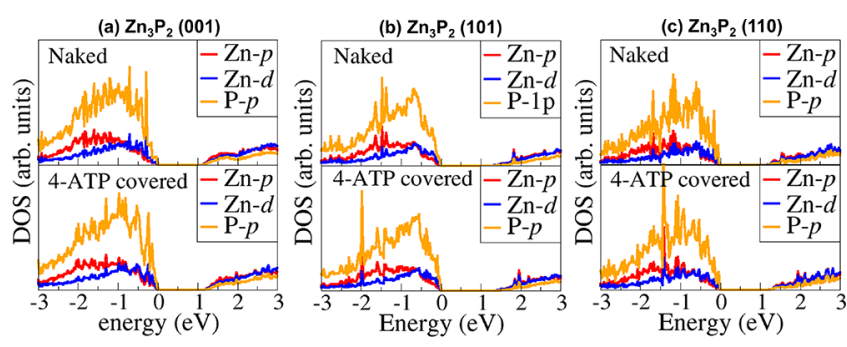

Figure 8. PDOS of the (a) (001), (b) (101), and (c) (110) $\mathrm{Zn}_{3} \mathrm{P}_{2}$ surfaces before (naked) and after 4ATP adsorption.

can be attributed to the small adsorption-induced changes to the atomic positions of the interacting surface species, which are displaced slightly upward relative to their position in the naked surfaces. The work function $(\Phi)$, which is one of the most important properties of surfaces in understanding photoemission and thermionic emission processes, was calculated for each $\mathrm{Zn}_{3} \mathrm{P}_{2}$ surface before and after 4ATP adsorption (Table 3). The work function was calculated as $\Phi=$

Table 3. Calculated Surface Energies $(\gamma)$ and Work Function $(\Phi)$ Before and After 4ATP Adsorption

\begin{tabular}{cccccc} 
& \multicolumn{2}{c}{ surface energy $\left(\mathrm{J} \mathrm{m}^{-2}\right)$} & & \multicolumn{2}{c}{ work function $(\mathrm{eV})$} \\
\cline { 2 - 3 } \cline { 5 - 6 } surface & $\gamma$ (naked) & $\gamma(4 \mathrm{ATP})$ & & $\Phi$ (naked) & $\Phi(4 \mathrm{ATP})$ \\
$\mathrm{Zn}_{3} \mathrm{P}_{2}(001)$ & 1.03 & 0.73 & & 4.32 & 4.07 \\
$\mathrm{Zn}_{3} \mathrm{P}_{2}(101)$ & 0.60 & 0.53 & & 4.79 & 4.67 \\
$\mathrm{Zn}_{3} \mathrm{P}_{2}(110)$ & 0.95 & 0.66 & & 4.75 & 4.42 \\
\hline
\end{tabular}

$E_{\text {vacuum }}-E_{\mathrm{F}}$, where the potential in the vacuum region $\left(E_{\text {vacuum }}\right)$ and the Fermi energy $\left(E_{\mathrm{F}}\right)$ were derived from the same calculation. Dipole corrections perpendicular to all surfaces were accounted for, which ensured that there is no net dipole perpendicular to the surfaces that may affect the potential in the vacuum level. The work function of the naked $\mathrm{Zn}_{3} \mathrm{P}_{2}$ (001), (101), and (110) surfaces is predicted at 4.32, 4.79 , and $4.75 \mathrm{eV}$, respectively, whereas the 4ATP-functionalized surfaces have calculated the work function of 4.07, 4.67, and $4.42 \mathrm{eV}$, respectively. The lowering of the work functions upon 4ATP adsorption can be attributed to the adsorptioninduced electron density redistribution in the 4ATP-surface systems. ${ }^{62-64}$ Besides, the adsorption acts to smoothen the surface electric charge distribution (the Smoluchowski effect) which lowers the work function. ${ }^{65,66}$

3.5. Equilibrium Crystal Morphologies. Following the procedure of Wulff construction and using the calculated surface energies of the naked and 4ATP-covered surfaces (Table 3), the equilibrium crystal morphology of the nonfunctionalized and 4ATP-functionalized $\mathrm{Zn}_{3} \mathrm{P}_{2}$ nanocrystal was constructed as shown in Figure 9. The adsorption of the 4ATP molecule is shown to have a stabilization effect on the three surfaces studied because the adsorption acts to coordinate the 4ATP molecule to the under coordinated $\mathrm{Zn}$ ions, thus providing a closer bulk coordination of the surface species. The stabilization of the surfaces is reflected in the lower surface energies calculated for the 4ATP-functionalized surfaces compared to the naked nonfunctionalized surfaces (Table 3). From Figure 9a, it can be seen that the (001), (110), and (001) facets appear in the nonfunctionalized $\mathrm{Zn}_{3} \mathrm{P}_{2}$ nanocrystals, although the (101) surface enclosed the largest areas, in agreement with its surface stability being the most stable among the three surfaces investigated. The (001) and

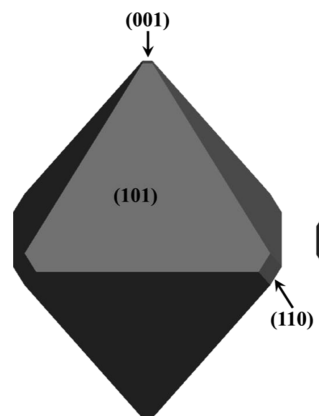

(a) $\mathrm{Zn}_{3} \mathrm{P}_{2}$

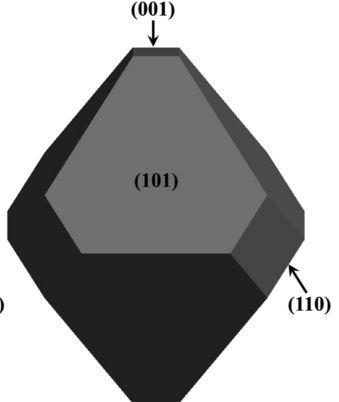

(b) 4-ATP- $\mathrm{Zn}_{3} \mathrm{P}_{2}$
Figure 9. Equilibrium Wulff shape of (a) nonfunctionalized and (b) 4ATP-functionalized $\mathrm{Zn}_{3} \mathrm{P}_{2}$ nanocrystal.

(110) facets enclose smaller areas in the nonfunctionalized $\mathrm{Zn}_{3} \mathrm{P}_{2}$ nanocrystal. From the adsorption studies, the stronger binding of the 4ATP molecule onto the (001) and (110) surfaces, rather than the (101) facet, causes the surface areas enclosed by these reactive surfaces to increase in the crystal morphology (Figure 9b). The increase in surface areas can be attributed to increased stability of the (001) and (110) surfaces upon 4ATP adsorption and this is consistent with many other crystals grown in the presence of growth-modifying ligands. ${ }^{21,67}$ The results demonstrate the selectivity of the 4ATP functional groups toward stabilizing the different $\mathrm{Zn}_{3} \mathrm{P}_{2}$ surfaces, favoring the expression of the more reactive surfaces in the particle morphology. Increasing the 4ATP coverage on the $\mathrm{Zn}_{3} \mathrm{P}_{2}$ surfaces may likely results in further expression of the reactive (001) and (110) surfaces in the equilibrium morphology.

\section{SUMMARY AND CONCLUSIONS}

The organic functionalization of the (001), (101), and (110) surface $\mathrm{Zn}_{3} \mathrm{P}_{2}$ with 4 ATP molecule has been studied by means of first-principles dispersion corrected DFT-D3 calculations. In particular, the effects of 4ATP adsorption on the structural and electronic properties of naked $\mathrm{Zn}_{3} \mathrm{P}_{2}$ surfaces have been elucidated. The lowest-energy adsorption geometries are predicted to be a monodentate $\mathrm{Zn}-\mathrm{S}$-slant configuration on the (001), monodentate $\mathrm{Zn}-\mathrm{S}$-flat configuration on the (101), and bidentate $\mathrm{Zn}-\mathrm{NS}-\mathrm{Zn}$ configuration on the (110) surfaces, which released adsorption energies of $-1.91,-1.21$, and $-1.35 \mathrm{eV}$, respectively. The adsorption of the 4ATP onto $\mathrm{Zn}_{3} \mathrm{P}_{2}$ surfaces is shown to be driven by strong hybridization between the 4ATP molecule's $S$ and $N$ p-orbitals and the $\mathrm{d}$ orbitals of the interacting surface $\mathrm{Zn}$ ions, which resulted in the formation of strong $\mathrm{Zn}-\mathrm{S}$ and $\mathrm{Zn}-\mathrm{N}$ chemical bonds. The final equilibrium morphology of $\mathrm{Zn}_{3} \mathrm{P}_{2}$ is modulated by 4ATP adsorption, with the reactive (001) and (110) surfaces becoming more pronounced in the equilibrium morphology relative to the (101) facet. The surface work function is shown to be lowered by 4ATP adsorption but the electronic band gap of the $\mathrm{Zn}_{3} \mathrm{P}_{2}$ surfaces remained significantly unaffected. This work provides an atomic-level understanding of the interactions of 4ATP species with $\mathrm{Zn}_{3} \mathrm{P}_{2}$ nanoparticles and the results discussed here may be relevant for future investigations of self-assembled 4ATP monolayers and other higher coverage structures. 


\section{ASSOCIATED CONTENT}

\section{S Supporting Information}

The Supporting Information is available free of charge at https://pubs.acs.org/doi/10.1021/acsomega.9b02736.

Schematic of the unrelaxed and relaxed structures of all unique terminations of the (001), (101), and (110) $\mathrm{Zn3P} 2$ surfaces with their predicted surface energies and unrelaxed and relaxed structures of the three unique terminations of $\mathrm{Zn3P2}$ (001), (101), and (110) (PDF)

\section{AUTHOR INFORMATION}

\section{Corresponding Author}

*E-mail: DzadeNY@cardiff.ac.uk.

ORCID

Nelson Y. Dzade: 0000-0001-7733-9473

Notes

The author declares no competing financial interest.

\section{ACKNOWLEDGMENTS}

N.Y.D. acknowledges the UK Engineering and Physical Sciences Research Council (EPSRC) for funding (grant no. $\mathrm{EP} / \mathrm{S} 001395 / 1)$. This work was performed using the computational facilities of the Advanced Research Computing @ Cardiff (ARCCA) Division, Cardiff University. This work also made use of the facilities of ARCHER (http://www.archer.ac. uk), the UK's national supercomputing service via our membership of the UK's HEC Materials Chemistry Consortium, which is funded by EPSRC (EP/L000202). Information on the data that underpins the results presented here, including how to access them, can be found in the Cardiff University data catalogue at http://doi.org/10.17035/d.2019. 0086503638.

\section{REFERENCES}

(1) Fagen, E. A. Optical properties of $\mathrm{Zn}_{3} \mathrm{P}_{2}$. J. Appl. Phys. 1979, 50, 6505-6515.

(2) Kimball, G. M.; Müller, A. M.; Lewis, N. S.; Atwater, H. A. Photoluminescence-based measurements of the energy gap and diffusion length of $\mathrm{Zn}_{3} \mathrm{P}_{2}$. Appl. Phys. Lett. 2009, 95, 112103 .

(3) Pawlikowski, J. M. Absorption edge of $\mathrm{Zn}_{3} \mathrm{P}_{2}$. Phys. Rev. B: Condens. Matter Mater. Phys. 1982, 26, 4711-4713.

(4) Wyeth, N. C.; Catalano, A. Spectral response measurements of minority-carrier diffusion length in $\mathrm{Zn}_{3} \mathrm{P}_{2}$. J. Appl. Phys. 1979, 50, $1403-1407$.

(5) Bosco, J. P.; Demers, S. B.; Kimball, G. M.; Lewis, N. S.; Atwater, H. A. Band alignment of epitaxial $\mathrm{ZnS} / \mathrm{Zn}_{3} \mathrm{P}_{2}$ heterojunctions. J. Appl. Phys. 2012, 112, 093703

(6) Bhushan, M.; Catalano, A. Polycrystalline $\mathrm{Zn}_{3} \mathrm{P}_{2}$ Schottky barrier solar cells. Appl. Phys. Lett. 1981, 38, 39-41.

(7) Kimball, G. M.; Lewis, N. S.; Atwater, H. A. Mg Doping and Alloying in $\mathrm{Zn}_{3} \mathrm{P}_{2}$ Heterojunction Solar Cells. 35th IEEE Photovoltaic Specialists Conference, 2010; pp 001039-001043.

(8) Bosco, J. P.; Scanlon, D. O.; Watson, G. W.; Lewis, N. S.; Atwater, H. A. Energy-band alignment of II-VI/ $\mathrm{Zn}_{3} \mathrm{P}_{2}$ heterojunctions from x-ray photoemission spectroscopy. J. Appl. Phys. 2013, 113, 203705.

(9) Kimball, G. M.; Bosco, J. P.; Müller, A. M.; Tajdar, S. F.; Brunschwig, B. S.; Atwater, H. A.; Lewis, N. S. Passivation of $\mathrm{Zn}_{3} \mathrm{P}_{2}$ substrates by aqueous chemical etching and air oxidation. J. Appl. Phys. 2012, 112, 106101.

(10) Chen, G.; Visbeck, S. B.; Law, D. C.; Hicks, R. F. Structuresensitive oxidation of the indium phosphide (001) surface. J. Appl. Phys. 2002, 91, 9362-9367.
(11) Soukiassian, P.; Bakshi, M. H.; Starnberg, H. I.; Bommannavar, A. S.; Hurych, Z. Precursor molecular-oxygen state in the initial catalytic oxidation of the $\operatorname{InP}(110)$ surface modified by alkali metals. Phys. Rev. B: Condens. Matter Mater. Phys. 1988, 37, 6496-6499.

(12) Bashouti, M. Y.; Stelzner, T.; Berger, A.; Christiansen, S.; Haick, H. Chemical Passivation of Silicon Nanowires with C-1-C-6 Alkyl Chains through Covalent Si-C Bonds. J. Phys. Chem. C 2008, $112,19168-19172$.

(13) Hanrath, T.; Korgel, B. A. Chemical Surface Passivation of Ge Nanowires. J. Am. Chem. Soc. 2004, 126, 15466-15472.

(14) Tao, A. R.; Habas, S.; Yang, P. Shape Control of Colloidal Metal Nanocrystals. Small 2008, 4, 310-325.

(15) Brockway, L.; Van Laer, M.; Kang, Y.; Vaddiraju, S. Large-scale synthesis and in situ functionalization of $\mathrm{Zn}_{3} \mathrm{P}_{2}$ and $\mathrm{Zn}_{4} \mathrm{Sb}_{3}$ nanowire powders. Phys. Chem. Chem. Phys. 2013, 15, 6260-6267.

(16) Mobarok, M. H.; Buriak, J. M. Elucidating the Surface Chemistry of Zinc Phosphide Nanoparticles Through Ligand Exchange. Chem. Mater. 2014, 26, 4653-4661.

(17) Li, H.; Yu, Y. H.; Vasiraju, V.; Vaddiraju, S.; Cheng, Z. of Electron Transport Through Alkanedithoil of Functionalized $\mathrm{Zn}_{3} \mathrm{P}_{2}$ Nanowires for Hydrogen Production. Int. J. Nano Stud. Technol. 2016, S1, 1-5.

(18) Vasiraju, V.; Kang, Y.; Vaddiraju, S. Non-conformal decoration of semiconductor nanowire surfaces with boron nitride (BN) molecules for stability enhancement: degradation-resistant $\mathrm{Zn}_{3} \mathrm{P}_{2}$, $\mathrm{ZnO}$ and $\mathrm{Mg}_{2} \mathrm{Si}$ nanowires. Phys. Chem. Chem. Phys. 2014, 16, 16150-16157.

(19) Nguyen, T.-D. From formation mechanisms to synthetic methods toward shape-controlled oxide nanoparticles. Nanoscale 2013, 5, 9455-9482.

(20) Burda, C.; Chen, X.; Narayanan, R.; El-Sayed, M. A. Chemistry and Properties of Nanocrystals of Different Shapes. Chem. Rev. 2005, $105,1025-1102$.

(21) Dzade, N. Y.; Roldan, A.; de Leeuw, N. H. Surface and shape modification of mackinawite (FeS) nanocrystals by cysteine adsorption: a first-principles DFT-D2 study. Phys. Chem. Chem. Phys. 2016, 18, 32007-32020.

(22) Sperling, R. A.; Parak, W. J. Surface modification, functionalization and bioconjugation of colloidal inorganic nanoparticles. Philos. Trans. R. Soc., A 2010, 368, 1333-1383.

(23) Dzade, N. Y.; de Leeuw, N. H.; de Leeuw, N. H. Adsorption and Desulfurization Mechanism of Thiophene on Layered $\mathrm{FeS}(001)$, (011), and (111) Surfaces: A Dispersion-Corrected Density Functional Theory Study. J. Phys. Chem. C 2018, 122, 359-370.

(24) Dzade, N. Y.; Roldan, A.; de Leeuw, N. H. Adsorption of methylamine on mackinawite ( $\mathrm{FeS}$ ) surfaces: A density functional theory study. J. Chem. Phys. 2013, 139, 124708.

(25) Wulff, G. On the Question of Speed of Growth and Dissolution of Crystal Surfaces. Z. Krystallogr. Mineral. 1901, 34, 449-530.

(26) Kresse, G.; Hafner, J. Ab initio molecular dynamics for liquid metals. Phys. Rev. B: Condens. Matter Mater. Phys. 1993, 47, 558.

(27) Kresse, G.; Hafner, J. Ab initio molecular-dynamics simulation of the liquid-metal-amorphous-semiconductor transition in germanium. Phys. Rev. B: Condens. Matter Mater. Phys. 1994, 49, 1425114269.

(28) Kresse, G.; Furthmüller, J. Efficient iterative schemes for ab initio total-energy calculations using a plane-wave basis set. Phys. Rev. B: Condens. Matter Mater. Phys. 1996, 54, 11169-11186.

(29) Blöchl, P. E. Projector augmented-wave method. Phys. Rev. B: Condens. Matter Mater. Phys. 1994, 50, 17953.

(30) Kresse, G.; Joubert, D. From ultrasoft pseudopotentials to the projector augmented-wave method. Phys. Rev. B: Condens. Matter Mater. Phys. 1999, 59, 1758.

(31) Perdew, J. P.; Burke, K.; Ernzerhof, M. Generalized Gradient Approximation Made Simple. Phys. Rev. Lett. 1997, 78, 1396.

(32) Perdew, J. P.; Burke, K.; Ernzerhof, M. Generalized Gradient Approximation Made Simple. Phys. Rev. Lett. 1996, 77, 3865-3868. 
(33) Liu, W.; Tkatchenko, A.; Scheffler, M. Modeling Adsorption and Reactions of Organic Molecules at Metal Surfaces. Acc. Chem. Res. 2014, 47, 3369-3377.

(34) Bedolla, P. O.; Feldbauer, G.; Wolloch, M.; Eder, S. J.; Dörr, N.; Mohn, P.; Redinger, J.; Vernes, A. Effects of van der Waals Interactions in the Adsorption of Isooctane and Ethanol on $\mathrm{Fe}(100)$ Surfaces. J. Phys. Chem. C 2014, 118, 17608-17615.

(35) Hamada, I.; Lee, K.; Morikawa, Y. Interaction of Water with a Metal Surface: Importance of van der Waals Forces. Phys. Rev. B: Condens. Matter Mater. Phys. 2010, 81, 115452.

(36) Grimme, S.; Antony, J.; Ehrlich, S.; Krieg, H. A consistent and accurate $\mathrm{ab}$ initio parametrization of density functional dispersion correction (DFT-D) for the 94 elements H-Pu. J. Chem. Phys. 2010, 132, 154104.

(37) Kristyán, S.; Pulay, P. Can (Semi)Local Density Functional Theory Account for the London Dispersion Forces? Chem. Phys. Lett. 1994, 229, 175-180.

(38) Israelachvili, J. N. Intermolecular and Surface Forces: Revised, 3rd ed.; Academic Press, 2011, eBook ISBN: 9780123919335.

(39) Da Silva, J. L. F.; Stampfl, C.; Scheffler, M. Adsorption of Xe Atoms on Metal Surfaces: New Insights from First-Principles Calculations. Phys. Rev. Lett. 2003, 90, 066104.

(40) Becke, A. D. Perspective: Fifty Years of Density-Functional Theory in Chemical Physics. J. Chem. Phys. 2014, 140, 18A301.

(41) Monkhorst, H. J.; Pack, J. D. Special points for Brillouin-zone integrations. Phys. Rev. B: Solid State 1976, 13, 5188.

(42) Sierański, K.; Szatkowski, J.; Misiewicz, J. Semiempirical tightbinding band structure of II3V2 semiconductors: Cd3P2, Zn3P2, Cd3As2, and Zn3As2. Phys Rev, B Condens Matter 1994, 50, 73317337.

(43) Weber, A.; Sutter, P.; von Känel, H. Optical, electrical, and photoelectrical properties of sputtered thin amorphous $\mathrm{Zn}_{3} \mathrm{P}_{2}$ films. J. Appl. Phys. 1994, 75, 7448.

(44) Misiewicz, J. Inter-band transitions in $\mathrm{Zn}_{3} \mathrm{P}_{2}$. J. Phys.: Condens. Matter 1990, 2, 2053.

(45) Zanin, I. E.; Aleinikova, K. B.; Afanasiev, M. M.; Antipin, M. Y. Structure of $\mathrm{Zn}_{3} \mathrm{P}_{2}$. J. Struct. Chem. 2004, 45, 844-848.

(46) Krukau, A. V.; Vydrov, O. A.; Izmaylov, A. F.; Scuseria, G. E. Influence of the exchange screening parameter on the performance of screened hybrid functionals. J. Chem. Phys. 2006, 125, 224106.

(47) Yin, W.-J.; Yan, Y. The electronic properties of point defects in earth-abundant photovoltaic material $\mathrm{Zn}_{3} \mathrm{P}_{2}$ : A hybrid functional method study. J. Appl. Phys. 2013, 113, 013708.

(48) Bae, I.-T.; Vasekar, P.; VanHart, D.; Dhakal, T. Lowtemperature synthesis of $\mathrm{Zn} 3 \mathrm{P} 2$ nanowire. J. Mater. Res. 2011, 26, $1464-1467$.

(49) Watson, G. W.; Kelsey, E. T.; de Leeuw, N. H.; Harris, D. J.; Parker, S. C. Atomistic simulation of dislocations, surfaces and interfaces in MgO. J. Chem. Soc., Faraday Trans. 1996, 92, 433-438.

(50) Tasker, P. W. The stability of ionic crystal surfaces. J. Phys. C: Solid State Phys. 1979, 12, 4977-4984.

(51) Makov, G.; Payne, M. C. Periodic boundary conditions in ab initio calculations. Phys. Rev. B: Condens. Matter Mater. Phys. 1995, 51, 4014.

(52) Tang, W.; Sanville, E.; Henkelman, G. A grid-based Bader analysis algorithm without lattice bias. J. Phys. Condens. Matter 2009, $21,084204$.

(53) Gibbs, J. W. Collected Works; Longmans, Green \& Co.: New York; London, 1928.

(54) Kim, K.; Han, J. W. Effect of caffeic acid adsorption in controlling the morphology of gold nanoparticles: role of surface coverage and functional groups. Phys. Chem. Chem. Phys. 2016, 18, 27775-27783.

(55) Fleming, S. D.; Rohl, A. L. GDIS. a visualization program for molecular and periodic systems. Z. Krist. 2005, 220, 1-5.

(56) Mkhonto, D.; de Leeuw, N. H. A computer modelling study of the effect of water on the surface structure and morphology of fluorapatite: introducing a $\mathrm{Ca}_{10}\left(\mathrm{PO}_{4}\right)_{6} \mathrm{~F}_{2}$ potential model. J. Mater. Chem. 2002, 12, 2633-2642.
(57) Santos-Carballal, D.; Roldan, A.; Grau-Crespo, R.; de Leeuw, N. H. A DFT study of the structures, stabilities and redox behaviour of the major surfaces of magnetite $\mathrm{Fe}_{3} \mathrm{O}_{4}$. Phys. Chem. Chem. Phys. 2014, 16, 21082-21097.

(58) Che, J. G.; Chan, C. T.; Jian, W.-E.; Leung, T. C. Surface atomic structures, surface energies, and equilibrium crystal shape of molybdenum. Phys. Rev. B: Condens. Matter Mater. Phys. 1998, 57, $1875-1880$.

(59) de Leeuw, N. H.; Parker, S. C. Surface Structure and Morphology of Calcium Carbonate Polymorphs Calcite, Aragonite, and Vaterite: An Atomistic Approach. J. Phys. Chem. B 1998, 102, 2914-2922.

(60) Di Felice, R.; Selloni, A.; Molinari, E. DFT Study of Cysteine Adsorption on $\mathrm{Au}(111)$. J. Phys. Chem. B 2003, 107, 1151-1156.

(61) Hayashi, T.; Morikawa, Y.; Nozoye, H. Adsorption state of dimethyl disulfide on $\mathrm{Au}(111)$ : Evidence for adsorption as thiolate at the bridge site. J. Chem. Phys. 2001, 114, 7615.

(62) Zhang, W.; Liu, L.; Wan, L.; Liu, L.; Cao, L.; Xu, F.; Zhao, J.; $\mathrm{Wu}, \mathrm{Z}$. Electronic structures of bare and terephthalic acid adsorbed $\mathrm{TiO}_{2}(110)-(1 \times 2)$ reconstructed surfaces: origin and reactivity of the band gap states. Phys. Chem. Chem. Phys. 2015, 17, 20144-20153.

(63) Ji, Y.; Du, Y.; Wang, M. Influence of Vacancy Defect on Surface Feature and Adsorption of Cs on $\mathrm{GaN}(0001)$ Surface. Sci. World J. 2014, 2014, 490853.

(64) Chou, S. H.; Voss, J.; Bargatin, I.; Vojvodic, A.; Howe, R. T.; Abild-Pedersen, F. An orbital-overlap model for minimal work functions of cesiated metal surfaces. J. Phys.: Condens. Matter 2012, 24,445007

(65) Singh-Miller, N. E.; Marzari, N. Surface energies, work functions, and surface relaxations of low-index metallic surfaces from first principles. Phys. Rev. B: Condens. Matter Mater. Phys. 2009, $80,235407$.

(66) Smoluchowski, R. Anisotropy of the Electronic Work Function of Metals. Phys. Rev. 1941, 60, 661.

(67) Cooper, T. G.; de Leeuw, N. H. A computer modelling study of the incorporation of $\mathrm{K}^{+}, \mathrm{Ca}^{2+}$ and $\mathrm{Mg}^{2+}$ impurities in two $\mathrm{Na}_{2} \mathrm{SO}_{4}$ polymorphs: Introducing a $\mathrm{Na}_{2} \mathrm{SO}_{4}$ potential model. J. Cryst. Growth 2006, 294, 137-149. 